\title{
A Buckling Model for the Stability Design of Steel Columns with Intermediate Gravity Loads
}

\author{
Lip H. Teh ${ }^{\mathrm{a},{ }^{*}}$, Benoit P. Gilbert ${ }^{\mathrm{b}}$ \\ ${ }^{a}$ School of Civil, Mining \& Environmental Engineering, University of Wollongong, Australia. \\ ${ }^{\mathrm{b}}$ Griffith School of Engineering, Griffith University, Australia. \\ *Corresponding author at School of Civil, Mining \& Environmental Engineering, University of Wollongong, \\ Wollongong, NSW 2522, Australia. Tel: +61242213564, fax: +61242213238, e-mail: $\underline{\text { teh@uow.edu.au }}$
}

\begin{abstract}
This paper points out an accurate buckling model for determining the flexural effective length of a steel column subjected to intermediate gravity loads, for applications in the $2 \mathrm{D}$ second-order elastic analysis based design procedure. The proposed buckling model has "notional" horizontal restraints where equivalent horizontal forces have been applied, and can be readily programmed into a structural analysis/design software. Thirty columns having various end restraint conditions and subjected to concentrated gravity loads within their unsupported lengths are analysed to demonstrate the merits of the proposed buckling model. It is shown that, in most of the cases analysed, the proposed buckling model leads to more liberal column capacities compared to the use of the unity effective length factor or the buckling model described in the European drive-in rack design code. The more liberal capacities are very close to the ultimate loads determined through second-order plastic-zone analysis.
\end{abstract}




\section{Introduction}

This paper is concerned with the stability design of steel columns subjected to intermediate gravity loads within their unsupported lengths, based on 2D second-order elastic analysis where the columns are assumed to have an initial out-of-plumb. Columns with intermediate gravity loads include mill building columns and drive-in rack uprights, shown in Figures 1 and 2, respectively. A three-dimensional view of an unloaded drive-in rack is shown in Figure 3. In steel storage rack design standards [1-4], the use of equivalent horizontal forces in lieu of explicit modelling of initial out-of-plumb (and connector looseness) is a wellaccepted practice. The equivalent horizontal forces are simply the product of the applied gravity loads and the prescribed initial out-of-plumb, as illustrated in Figure 4, which is adopted from the European adjustable pallet racking code [1].

The concept of equivalent horizontal forces is predated by the notional load approach found in the literature [5-7], which aims to capture the initial out-of-plumb $(P-\Delta)$, initial crookedness $(P-\delta)$, distributed plasticity and residual stress effects on the member forces at the ultimate limit state via the application of notional horizontal loads in a second-order analysis. However, the equivalent horizontal forces in the storage rack design standards correspond more closely to the notional horizontal loads specified in the current structural steel design standards [8-9], which principally model the frame's (nominal) initial out-ofplumb only, although Section 3.3.2.1 of the Australian storage racking standard [4] attempts to account for inelasticity via a minimum value of the initial out-of-plumb that is greater for the second-order elastic analysis than for the second-order inelastic analysis.

The notional load approach has been promoted as a method that enables the use of the "actual unsupported length" of a column in its stability design check. With regard to regular rectangular frames, extensive discussions regarding effective lengths and the notional load approach can be found in the literature [10-16]. Surovek \& White [13] proposed the "modified elastic approach", which forms the basis of the highly successful "Direct Analysis Method" described in the current AISC Specification for Structural Steel Buildings [9]. They stated that the LRFD-based notional load approach [7] had a limitation in that the moments produced by the notional horizontal loads are distributed through the system based on the elastic stiffness, causing the lateral load resisting part that has the largest elastic stiffness to receive a higher portion of the notional load effects regardless of the level of the axial load 
and subsequent inelasticity of individual beam-columns. However, this observation does not apply to certain structures such as the drive-in rack shown in Figure 2.

First, in general the stiffness is quite uniform throughout the drive-in rack system since the uprights are of the same size. Furthermore, the uprights within a down-aisle plane of bending generally carry the same design load. Second, in most cases the main lateral load resisting system is the spine bracing located in one down-aisle plane (most often at the back) that functions in conjunction with the plan bracing at the top of rack [17], as illustrated in Figure 3. Third, the notional horizontal load effects (in the down-aisle direction) are substantially local to the uprights where they are applied since there are no beams connecting the uprights to each other except at the top, as evident in Figure 3. It may also be noted that there is no inelastic moment redistribution in a drive-in rack.

The exception mentioned in the preceding paragraph also applies to mill building columns [18-21]. As indicated previously, in addition to the exception common to drive-in rack uprights and mill building columns, these compression members also share an important feature, i.e. they are subjected to intermediate gravity loads within their unsupported lengths.

In contrast to regular rectangular frames, very little discussions can be found on the application of the notional load approach to a column subjected to intermediate gravity loads within its unsupported length. It is unclear to the structural engineer what the correct flexural effective length is for the bottom segment, or any of the upper segments, even when he or she uses the notional load approach or the equivalent horizontal forces. What is the "actual unsupported length" in this case? Based on the authors' experience, it is a common belief that the use of an effective length factor equal to unity for each segment is unconservative, since there are no horizontal members connecting the column at each loaded point to adjacent columns (i.e. there are no lateral restraints at the ends of each segment). This belief appears to be justified by Clause 9.4.3 of the European drive-in rack design code [2], which specifies that only the base and the top of the upright are to be laterally restrained in the buckling model used to determine the effective length when "direct second-order analysis" method is carried out, resulting in flexural effective length factors greater than unity in most cases.

However, it will be explained and demonstrated in this paper that whether there is a horizontal member restraining the point of loading or not is irrelevant to the correct buckling model used to determine the flexural effective length. For drive-in racks, the buckling model 
is also independent of the horizontal restraints provided by the friction between the pallet bases and the pallet runners [22].

This paper aims to elucidate the implications of the equivalent horizontal forces, and explain the more economical procedure for determining the (elastic) flexural effective length of a column subjected to intermediate gravity loads within its unsupported length. The buckling model proposed in this paper can be applied to the design of drive-in rack uprights and mill building columns, where automated creation of buckling models with no manual efforts from the program user has been implemented for several years [23]. In the warehousing industry, "little" savings in the member sizing quickly add up due to extensive repeatability. Furthermore, missing the required capacity by $5 \%$ often means an increase in steel tonnage of $25 \%$ or more due to a step change in the member sizes.

As this paper is only concerned with the determination of the flexural effective length of a column in a 2D second-order elastic analysis based design procedure, three-dimensional phenomena such as torsional warping and flexural-torsional buckling [24-26] are not discussed. This paper reviews the failure mechanism of a compact steel column and points out its implication for the notional load approach. Based on the second-order plastic-zone analysis results of thirty columns subjected to intermediate gravity loads within their unsupported lengths, the proposed buckling model is compared against the use of the unity effective length factor and the buckling model prescribed in Clause 9.4.3 of the European drive-in rack design code [2].

\section{How a (compact) steel column reaches its ultimate load capacity}

The failure mechanism of a steel column may appear to be a simple topic, but its fundamental has sometimes eluded practitioners and researchers in the field. A steel column, no matter how slender it is, does not reach its ultimate load-carrying capacity when it buckles elastically, but after the critical cross-section has yielded sufficiently under combined compression and bending. Figure 5, adapted from Gere \& Timoshenko [27], shows that a column that has buckled elastically is able to sustain increased loading beyond the elastic buckling load $P_{\mathrm{e}}$.

Curve $\mathrm{A}$ in the figure denotes the load-deflection path of an elastic, geometrically perfect column following its bifurcation. Curve B denotes that of an elastic, initially crooked column. The softening response exhibited by this curve is due to the $P$ - $\delta$ effect. In each of the two 
cases, as long as the column remains elastic, it can always sustain increased loading since the column's resistance increases with increasing deformations to the extent that it equilibrates the applied load.

However, in reality, a (compact) steel column that buckles elastically would soon reach its ultimate load-carrying capacity as it encounters member instability due to (partial) yielding of the critical cross-section under combined compression and bending. For a simply supported column such as that shown in Figure 5(a), the bending moment at mid-span (the critical cross-section) results from the so-called $P-\delta$ effect. At the ultimate limit state, any further increase in the bending resistance of the mid-span due to increasing deformation could only match the increase in the $P$ - $\delta$ effect if the applied load $P$ decreases (while the displacement $\delta$ increases disproportionately).

As an aside, the failure mechanism described in the preceding paragraph is sometimes simplified into the formation of a plastic hinge at the critical cross-section [5], or into a crosssection failure (which may also be due to local or distortional buckling), which is implicit in Clause 9.4.2 of FEM 10.2.07 [2]. According to this clause, only the cross-section strength check is required if the second-order elastic analysis accounts for the member's initial crookedness in addition to the initial out-of-plumb. Such a procedure may be justified if the member is stocky or bent in substantial double curvature as the cross-section strength governs the design in these cases. It is optimistic otherwise since it ignores the member instability described in the preceding paragraph unless the notional load is calibrated [5].

Real steel columns are invariably subject to initial crookedness, so a steel column typically follows the path denoted by Curve $\mathrm{C}$ in Figure 5(b). In any case, the ultimate load capacity of a column of a given section depends largely on its effective length $L_{\mathrm{e}}$, while the variation in the magnitudes of the initial crookedness $\delta_{0}$ typically encountered in practice has relatively insignificant effects on the ultimate capacity, as demonstrated by Teh \& Clarke [28] for a square hollow section. The cantilevered and simply supported columns in Figure 6 have essentially the same ultimate load if they are composed of the same section. Based on this premise, column curves are used in steel structures design standards [8-9, 29], where these curves may be represented by mathematical functions. The member compression capacity of an initially crooked column is determined from its effective length and the relevant column curve, which is typically derived for the simply supported condition (for which the effective length factor is unity). 


\section{Implication of the notional horizontal load}

As illustrated in Figure 4, the equivalent horizontal forces prescribed in steel design standards [1-3, 8-9] model the frame's initial out-of-plumb. It has also been established by Clarke \& Bridge [6] that the bending moments in the columns resulting from the application of the equivalent horizontal forces are virtually equal to those due to the initial out-of-plumb.

As indicated in the preceding section, the ultimate load $P_{\mathrm{u}}$ of an axially loaded cantilevered column such as that shown in Figure 6(a) can be determined directly from the relevant column curve and its effective length, which is twice its actual length, i.e. $P_{\mathrm{u}}=P_{\mathrm{c}}\left(L_{\mathrm{e}}=2 L_{2}\right)$. Viewed as an equivalent simply supported column having a length twice its actual length, shown in Figure 6(b), no interaction equation between axial force and bending moment needs to be considered in determining its ultimate load capacity.

The free body, axial force and bending moment diagrams of the cantilevered column at the ultimate limit state, the latter two drawn for the assumed straight configuration, are shown in Figure 7. The bending moment $M_{\mathrm{u}}$ at the column base, which is due to the $P-\Delta$ effect, can be "reasonably" found through a second-order elastic analysis where the initial out-of-plumb $\Delta_{0}$ of the cantilevered column is modelled, either explicitly or via an equivalent horizontal force. Viewed in this manner, it is clear that the column fails by the interaction between the axial force and the bending moment, and its capacity can be determined using the appropriate interaction equation. For bi-symmetric I-sections, and rectangular and square hollow sections that are compact, AS 4100 [8] specifies the following interaction equation where the ultimate moment $M_{u}$ is given as

$$
M_{u}=M_{s}\left\{\left[1-\left(\frac{1+\beta_{m}}{2}\right)^{3}\right]\left(1-\frac{P_{u}}{P_{c}^{\prime}}\right)+1.18\left(\frac{1+\beta_{m}}{2}\right)^{3} \sqrt{\left(1-\frac{P_{u}}{P_{c}^{\prime}}\right)}\right\}
$$

in which $M_{\mathrm{s}}$ is the section moment capacity, and $\beta_{\mathrm{m}}$ is the ratio of the smaller to the larger end moment, taken as positive when the column is bent in double curvature. The compression capacity $P_{\mathrm{c}}{ }^{\prime}$ is discussed in the next paragraph. The capacity factor $\phi$ given in the design standard [8] has been omitted from Equation (1). Interested readers may consult references [30-31] for the derivation and application of the design equation.

It is obvious that, for the cantilevered column, the compression capacity $P_{\mathrm{c}}{ }^{\prime}$ in Equation (1) must be greater than the ultimate load $P_{\mathrm{u}}=P_{\mathrm{c}}\left(L_{e}=2 L_{2}\right)$. In fact, the structural steel design 
standards [8-9] specify that the compression capacity $P_{\mathrm{c}}{ }^{\prime}$ to be used in the interaction equation is equal to $P_{\mathrm{c}}\left(L_{e}=L_{2}\right)$, i.e. the effective length factor is unity whether the member is braced or unbraced at both ends.

The exposition in the preceding paragraph should resolve the doubt among drive-in rack designers whether an effective length factor of unity can be safely applied to, say, the bottom segment of an upright when equivalent horizontal forces are included in the second-order analysis. In fact, as will be demonstrated later in this paper, the use of an effective length factor equal to unity in the interaction equation can be quite conservative in certain cases. The more correct procedure for determining the flexural effective length of a column segment is to apply a "notional" horizontal restraint where an equivalent horizontal force has been applied, in the buckling model. Figure 8(b) depicts the buckling model for the cantilevered column, which would result in an effective length factor close to 0.7 (equal to 0.699 in three significant figures).

The notional horizontal restraint should be imposed onto the buckling model since the interaction equation is used to check the second-order bending moment resulting from the $P$ $\Delta$ effect. In other words, the destabilising effect due to the absence of a lateral restraint has been represented in the second-order analysis, and should not be duplicated in the buckling model to determine the effective length and therefore $P_{\mathrm{c}}{ }^{\prime}$ in Equation (1). However, the implication of amplifying the bending moments due to the initial out-of-plumb (or equivalent horizontal forces) is less well appreciated in the literature, as reflected in the buckling model prescribed or allowed by certain standards $[2,8]$.

As far as computer analysis programs such as RAD [23] are concerned, a notional horizontal restraint can be automatically imposed onto the buckling model at any node where an equivalent horizontal force has been applied in the second-order elastic analysis.

In addition to the member stability check represented by Equation (1), AS 4100 [8] requires that the member is checked against cross-section strength, which, for a compact rectangular or square hollow section, is represented by

$$
M_{u}=1.18 M_{s}\left(1-\frac{P_{u}}{P_{y}}\right)
$$


in which $P_{\mathrm{y}}$ is the squash load. However, as mentioned earlier, the cross-section strength check only governs stocky columns and those bent in substantial double curvature. The capacity factor $\phi$ is omitted from the equation.

\section{Demonstration problems}

All the columns analysed in this paper are composed of square hollow section (SHS) $203 \times$ 6.3. This section was selected for three reasons. First, the issues of local, distortional, minor/major axis and flexural-torsional buckling are irrelevant to the square hollow section, ensuring proper evaluations of the alternative methods used to determine the flexural effective length. Second, an interaction equation that accounts for the bending moment gradient, namely Equation (1), is available for a square hollow section, enabling a more rigorous comparison of the various buckling models considered in this paper. Third, simply supported columns of various lengths composed of this section had been tested and analysed by Key \& Hancock [32], who provided the finite strip analysis results including that neglecting residual stresses. The finite element models used in the present plastic-zone analyses [33] could therefore be verified and employed with confidence.

The square hollow section has an area of $4,818 \mathrm{~mm}^{2}$ and a second moment of area equal to $3.06 \times 10^{7} \mathrm{~mm}^{4}$. The slenderness ratios $L / r$ in the following problems range from 37 to 113 .

For the purpose of this paper, the square hollow section was assumed to have a uniform yield stress of $395 \mathrm{MPa}$, which is the same as the flange yield stress in the analytical model of Key \& Hancock [32]. No residual stresses nor strain hardening was assumed. The demonstration column models had an initial out-of-plumb $\xi=0.002$ in both the second-order plastic and elastic analyses unless noted otherwise. However, no initial crookedness was modelled in the second-order elastic analyses as per the standard practice, while an initial crookedness $\delta_{0}$ of $L / 1000$ was invariably modelled in the plastic-zone analyses, the direct results of which are taken to be the correct ones.

In the following discussion, Method A refers to the use of the unity effective length factor to determine the compression capacity $P_{\mathrm{c}}^{\prime}$ that is entered into Equation (1), and Method B refers to the use of the present buckling model, in which notional horizontal restraints are imposed where the equivalent horizontal forces have been applied. The effective length factors in Method B are therefore invariably smaller than in Method A, often significantly so. 
The third method, called Method C, uses the buckling model described in Clause 9.4.3 of FEM 10.2.07 [2]. The buckling model is only relevant to the columns subjected to intermediate gravity loads within its unsupported length, and is shown in the following subsections where applicable.

Having determined the effective length of a column or column segment, the compression capacity $P_{\mathrm{c}}{ }^{\prime}$ to be entered into Equation (1) is read from the column curve shown in Figure 9. This curve has been derived through a series of plastic-zone analyses of simply supported columns having lengths ranging from $100 \mathrm{~mm}$ to $18,000 \mathrm{~mm}$. Each of these columns was assumed to have an initial crookedness $\delta_{0}$ of $L / 1000$.

\subsection{Cantilevered columns axially loaded at the top}

This simple structure, depicted in Figure 8(a), is included in this paper to demonstrate that Equation (1) is not unduly conservative. This aspect is important since, in the following subsections, it will be asserted that the use of an effective length factor equal to unity (Method A), and the buckling model described in Clause 9.4.3 of FEM 10.2.07 [2] that is used in Method C, lead to significant conservatism in the design of certain columns.

The buckling model used to determine the effective lengths in the present method (Method B) is depicted in Figure 8(b), which results in an elastic effective length factor equal to 0.7 .

Table 1 lists the professional factors $P_{\mathrm{ua}} / P_{\mathrm{ud}}$ of Methods A and B for 3000, 6000 and 9000 mm long columns. The variable $P_{\text {ua }}$ denotes the ultimate load obtained by the second-order plastic-zone analysis, and $P_{\mathrm{ud}}$ is the ultimate load capacity determined through second-order elastic analysis in conjunction with Equations (1) and (2), which depends on the effective length used to read $P_{\mathrm{c}}{ }^{\prime}$ from the column curve shown in Figure 9.

Table 1 Results for cantilevered columns with $\xi=0.002$

\begin{tabular}{ccccccc}
\hline \multirow{2}{*}{ Case } & $\boldsymbol{L}(\mathbf{m m})$ & $\boldsymbol{P}_{\mathrm{ua}}(\mathbf{k N})$ & \multicolumn{3}{c}{$\operatorname{Method~A}\left(\boldsymbol{L}_{\mathrm{e}}=\boldsymbol{L}\right)$} & \multicolumn{2}{c}{ Method B $\left(\boldsymbol{L}_{\mathrm{e}}=\mathbf{0 . 7} \boldsymbol{L}\right)$} \\
\cline { 4 - 7 } & & $\boldsymbol{P}_{\mathbf{c}}{ }^{\prime}(\mathbf{k N})$ & $\boldsymbol{P}_{\mathrm{ua}} / \boldsymbol{P}_{\mathbf{u d}}$ & $\boldsymbol{P}_{\mathbf{c}}{ }^{\prime}(\mathbf{k N})$ & $\boldsymbol{P}_{\mathbf{u a}} / \boldsymbol{P}_{\mathbf{u d}}$ \\
\hline 4.1 .1 & 3000 & 1289 & 1802 & 0.94 & 1841 & 0.94 \\
4.1 .2 & 6000 & 394 & 1323 & 0.98 & 1689 & 0.98 \\
4.1 .3 & 9000 & 180 & 684 & 0.99 & 1238 & 0.99 \\
\hline
\end{tabular}


It can be seen from Table 1 that, for a cantilevered column axially loaded at the top, significant differences in the assumed effective length factors do not lead to noticeably different ultimate load capacities $P_{\mathrm{ud}}$. For the 3000 -mm column, the compression capacity $P_{\mathrm{c}}{ }^{\prime}$ entered into Equation (1) for the unity effective length factor is only $2 \%$ lower than that for the effective length factor of 0.7. For the other two columns, the reasons are twofold. First, a given percentage difference in the compression capacities $P_{\mathrm{c}}{ }^{\prime}$ translate to a much smaller one in the available moment capacities $M_{\mathrm{u}}$ given by Equation (1). Second, in the proximity of the ultimate load $P_{\mathrm{u}}$, the second-order bending moment increases much more rapidly than the applied load.

However, when either method is used, the ultimate load capacity $P_{\text {ua }}$ of the $3000-\mathrm{mm}$ column is overestimated by more than 5\% (Case 4.1.1 in Table 1). The reason is that the second-order bending moment at the ultimate limit state, which is the result of the $P-\Delta$ effect, is underestimated by the second-order elastic analysis. The elastic displacement of the 3000$\mathrm{mm}$ column is about $30 \%$ less than the inelastic displacement at the ultimate limit state, as evident in Figure 10. For each case shown in Figure 10, the elastic curve is somewhat stiffer than the inelastic one, which is plotted thicker, due to the neglect of initial crookedness in the former and, for Case 4.1.1, subsequent inelasticity in the latter.

According to AS/NZS 4084 [4], the minimum initial out-of-plumb $\xi$ is equal to 0.004 when second-order elastic analysis is performed, and 0.002 when second-order inelastic analysis is used. Table 2 shows the professional factors of both methods when $\xi=0.004$ is used in the second-order elastic analysis.

Table 2 Results for cantilevered columns with $\xi=0.004$ in the elastic analysis

\begin{tabular}{cccccc}
\hline \multirow{2}{*}{$(\mathbf{m m})$} & $\boldsymbol{P}_{\text {ua }}(\mathbf{k N})$ & \multicolumn{2}{c}{ Method A $\left(\boldsymbol{L}_{\mathrm{e}}=\boldsymbol{L}\right)$} & \multicolumn{2}{c}{ Method B $\left(\boldsymbol{L}_{\mathrm{e}}=\mathbf{0 . 7} \boldsymbol{L}\right)$} \\
\cline { 3 - 6 } & & $\boldsymbol{P}_{\mathbf{c}}{ }^{\prime}(\mathbf{k N})$ & $\boldsymbol{P}_{\mathbf{u a}} / \boldsymbol{P}_{\mathbf{u d}}$ & $\boldsymbol{P}_{\mathbf{c}}{ }^{\prime}(\mathbf{k N})$ & $\boldsymbol{P}_{\mathbf{u a}} / \boldsymbol{P}_{\mathbf{u d}}$ \\
\hline 3000 & 1289 & 1802 & 1.05 & 1841 & 1.04 \\
6000 & 394 & 1323 & 1.02 & 1689 & 1.01 \\
9000 & 180 & 684 & 1.01 & 1238 & 1.01 \\
\hline
\end{tabular}

The results shown in Tables 1 and 2 may appear to be inconsistent with each other as the professional factors vary in the opposite ways with respect to the column slenderness. However, Clarke \& Bridge [6] have found that, for the second-order elastic analysis based design procedure to exactly match the plastic-zone analysis results, the required notional 
horizontal load increases with the column slenderness. There is therefore no inconsistency in the professional factors between Tables 1 and 2.

In any case, Table 1 demonstrates that the use of Equations (1) and (2) in conjunction with an initial out-of-plumb $\xi=0.002$ in the second-order elastic analysis does not lead to conservatism for the SHS columns analysed in the present work. This finding means that the two equations are unlikely to be the source of any significant conservatism found in the following examples.

\subsection{Columns with fixed bases and elastic restraints at the loading point}

The example depicted in Figure 11(a) is interesting in that it demonstrates the conservatism of the unity effective length factor approach (Method A) in a certain case where the actual (elastic) effective length factor of the column is 1.0. Method B uses the buckling model depicted in Figure 11(b).

This example also illustrates the consequence of using the same initial out-of-plumb in the second-order plastic and elastic analyses, which does not vary monotonically with the column slenderness. Another feature of this example is that, except for Cases 4.2.2 and 4.2.3 listed in Table 3, the cross-section strength represented by Equation (2) governs when the proposed method (Method B) is used to determine the compression capacity $P_{\mathrm{c}}^{\prime}$ to be entered into Equation (1).

Table 3 Results for columns with fixed bases and elastic restraints at the loading point

\begin{tabular}{|c|c|c|c|c|c|c|c|c|}
\hline \multirow{2}{*}{ Case } & \multirow{2}{*}{$L(\mathbf{m m})$} & \multirow{2}{*}{$K_{t}^{\prime}$} & \multirow{2}{*}{$\boldsymbol{K}_{r}^{\prime}$} & \multirow{2}{*}{$P_{\text {ua }}(\mathbf{k N})$} & \multicolumn{2}{|c|}{ Method A $\left(L_{\mathrm{e}}=L\right)$} & \multicolumn{2}{|c|}{ Method B (Fig. 11b) } \\
\hline & & & & & $P_{\mathrm{c}}{ }^{\prime}(\mathrm{kN})$ & $P_{\text {ua }} / P_{\text {ud }}$ & $P_{\mathrm{c}}^{\prime}(\mathbf{k N})$ & $P_{\mathrm{ua}} / P_{\mathrm{ud}}$ \\
\hline 4.2 .1 & 5000 & 1 & 1 & 1633 & 1560 & 1.06 & 1807 & $0.97(0.93)$ \\
\hline 4.2 .2 & & 3 & 1 & 1777 & & 1.14 & & 0.99 \\
\hline 4.2 .3 & & 3 & 3 & 1778 & & 1.14 & 1817 & 0.98 \\
\hline 4.2 .4 & 7500 & 1 & 1 & 1022 & 949 & 1.12 & 1680 & $1.01(0.99)$ \\
\hline 4.2 .5 & & 3 & 1 & 1384 & & 1.46 & & $0.95(0.93)$ \\
\hline 4.2 .6 & & 3 & 3 & 1438 & & 1.52 & 1720 & $0.95(0.91)$ \\
\hline
\end{tabular}

Note: If the cross-section strength governs, the professional factor resulting from Equation (1) is given in brackets. 
The normalised translational spring stiffness $K_{\mathrm{t}}^{\prime}$ in Table 3 and subsequent tables is defined as

$$
K_{t}^{\prime}=\frac{k_{t} L^{3}}{3 E I}
$$

in which $E$ is the column's elastic modulus and $I$ is its second moment of area. Therefore, a value of $K_{\mathrm{t}}^{\prime}=1.0$ implies that the cantilevered column is translationally restrained by another identical (unloaded) column that is connected at the top via a pin-ended link.

The normalised rotational spring stiffness $K_{\mathrm{r}}{ }^{\prime}$ is defined as

$$
K_{r}^{\prime}=\frac{k_{r} L}{6 E I}
$$

An empty cell in Table 3 means that it has the same value as the above cell. This convention applies to all tables in this paper.

Table 3 shows that, even for Case 4.2.4, where the actual (elastic) effective length factor is equal to 1.0 , the use of the unity effective length factor leads to some conservatism. The conservatism quickly escalates as the translational restraint increases. Note that the columns $(\xi=0.002)$ sway rather significantly under axial compression alone, as evident from the loaddeflection graphs plotted in Figure 12.

It can be seen from Table 3 that, even if the same initial out-of-plumb $\xi=0.002$ is used in both the second-order plastic and elastic analyses, the use of the proposed buckling model depicted in Figure 11(b) in conjunction with Equations (1) and (2) does not lead to overoptimistic capacities by more than $5 \%$. This outcome is despite the $27 \%$ underestimation of the tip displacement at the ultimate limit state (and therefore the $P-\Delta$ effect) of Case 4.2 .5 by the second-order elastic analysis, as evident in Figure 12. For each case shown in Figure 12, the elastic curve is noticeably stiffer than the inelastic one, which is plotted thicker.

Additional analysis results involving propped columns are shown in Table 4. It can be seen that Method A resulted in similar levels of conservatism to those shown in Table 3. The proposed Method B, on the other hand, is consistently accurate for the propped columns. 
Table 4 Results for propped columns with elastic rotational restraints

\begin{tabular}{|c|c|c|c|c|c|c|c|c|}
\hline \multirow{2}{*}{ Case } & \multirow{2}{*}{$L(\mathbf{m m})$} & \multirow{2}{*}{$K_{t}^{\prime}$} & \multirow{2}{*}{$\boldsymbol{K}_{r}^{\prime}$} & \multirow{2}{*}{$P_{\text {ua }}(\mathrm{kN})$} & \multicolumn{2}{|c|}{ Method A $\left(L_{\mathrm{e}}=L\right)$} & \multicolumn{2}{|c|}{ Method B (Fig. 11b) } \\
\hline & & & & & $P_{\mathrm{c}}{ }^{\prime}(\mathrm{kN})$ & $P_{\mathrm{ua}} / P_{\mathrm{ud}}$ & $P_{\mathrm{c}}{ }^{\prime}(\mathrm{kN})$ & $P_{\mathrm{ua}} / P_{\mathrm{ud}}$ \\
\hline 4.2 .7 & 5000 & $\infty$ & 0 & 1775 & 1560 & 1.14 & 1764 & 1.01 \\
\hline 4.2 .8 & & & 3 & 1835 & & 1.18 & 1817 & 1.01 \\
\hline 4.2 .9 & 7500 & & 0 & 1532 & 949 & 1.61 & 1498 & 1.02 \\
\hline 4.2 .10 & & & 3 & 1741 & & 1.83 & 1720 & 1.01 \\
\hline
\end{tabular}

\subsection{Columns with one intermediate gravity load}

The example depicted in Figure 13(a) has a loading arrangement that may be encountered in mill building columns (see also Problem 4.6), and shows cases where Methods A and C are alternately overconservative while Method B, which uses the buckling model depicted in Figure 13(b), is consistently accurate. The buckling model used by Method C, described in Clause 9.4.3 of FEM 10.2.07 [2], is shown in Figure 13(c). The "actual unsupported length" in Method A is the loaded length $L_{\mathrm{b}}$.

For the columns considered in Table 5, the second-order analysis model shown in Figure 13(a) coincides with the buckling model depicted in Figure 13(c).

Table 5 Results for columns with one intermediate gravity load

\begin{tabular}{|c|c|c|c|c|c|c|c|c|c|c|}
\hline \multirow{2}{*}{ Case } & \multirow{2}{*}{$K_{r}^{\prime}$ bot } & \multirow{2}{*}{$K_{t}^{\prime}$ top } & \multirow{2}{*}{$K_{r}^{\prime}$ top } & \multirow{2}{*}{$P_{\mathrm{ua}}(\mathbf{k N})$} & \multicolumn{2}{|c|}{ Method A } & \multicolumn{2}{|c|}{ Method B } & \multicolumn{2}{|c|}{ Method C } \\
\hline & & & & & $P_{\mathrm{c}}^{\prime}(\mathrm{kN})$ & $\boldsymbol{P}_{\text {ua }} / \boldsymbol{P}_{\text {ud }}$ & $P_{\mathrm{c}}{ }^{\prime}(\mathrm{kN})$ & $P_{\text {ua }} / P_{\text {ud }}$ & $P_{\mathrm{c}}{ }^{\prime}(\mathrm{kN})$ & $P_{\mathrm{ua}} / \boldsymbol{P}_{\mathrm{ud}}$ \\
\hline 4.3 .1 & 0 & $\infty$ & 0 & 1203 & 1324 & 1.07 & 1600 & 1.02 & 1098 & 1.18 \\
\hline 4.3 .2 & 1 & $\infty$ & 1 & 1765 & & 1.33 & 1721 & 1.03 & 1624 & 1.09 \\
\hline
\end{tabular}

Table 5 shows that, for the pin-ended column (Case 4.3.1), the buckling model described in Clause 9.4.3 of FEM 10.2.07 [2] and used in Method C leads to an underestimation of the ultimate load capacity by almost $20 \%$. For the column with elastic rotational restraints (Case 4.3.2), the use of the unity effective length factor underestimates same by more than $30 \%$. On the other hand, Method B is consistently accurate for both columns.

Additional analysis results for columns each of which is subjected to a gravity load within its unsupported length are shown in Table 6. Method B is again consistently accurate for all columns. 
Table 6 Additional results for columns with one intermediate gravity load

\begin{tabular}{|c|c|c|c|c|c|c|c|c|c|c|}
\hline \multirow{2}{*}{ Case } & \multirow{2}{*}{$\boldsymbol{K}_{r}^{\prime}$ bot } & \multirow{2}{*}{$K_{t}^{\prime}$ top } & \multirow{2}{*}{$\boldsymbol{K}_{r}^{\prime}$ top } & \multirow{2}{*}{$P_{\text {ua }}(\mathbf{k N})$} & \multicolumn{2}{|c|}{ Method A } & \multicolumn{2}{|c|}{ Method B } & \multicolumn{2}{|c|}{ Method C } \\
\hline & & & & & $P_{\mathrm{c}}^{\prime}(\mathrm{kN})$ & $P_{\mathrm{ua}} / P_{\mathrm{ud}}$ & $P_{c}^{\prime}(\mathrm{kN})$ & $P_{\mathrm{ua}} / P_{\mathrm{ud}}$ & $P_{\mathrm{c}}^{\prime}(\mathrm{kN})$ & $P_{\mathrm{ua}} / \boldsymbol{P}_{\mathrm{ud}}$ \\
\hline 4.3 .3 & 3 & $\infty$ & 3 & 1806 & 1324 & 1.36 & 1756 & 1.03 & 1706 & 1.06 \\
\hline 4.3.4 & 1 & 1 & 1 & 771 & & 1.02 & 1645 & 1.02 & 1626 & 1.02 \\
\hline 4.3 .5 & 1 & 3 & 1 & 1182 & & 1.04 & 1653 & 1.02 & 1626 & 1.02 \\
\hline 4.3.6 & $\infty$ & 3 & $\infty$ & 1368 & & 1.10 & 1743 & 1.01 & 1743 & 1.01 \\
\hline
\end{tabular}

\subsection{Columns with two equally spaced gravity loads}

The example depicted in Figure 14(a) has a loading arrangement that may be encountered in drive-in racks. The three methods of determining the effective length are compared across three different restraint conditions at the bottom and the top. Method A invariably uses the length of each segment, $5000 \mathrm{~mm}$, as the effective length. Method B uses the buckling model depicted in Figure 14(b), while Method C uses that in Figure 14(c).

Table 7 Results for columns with two equally spaced gravity loads

\begin{tabular}{|c|c|c|c|c|c|c|c|c|c|c|}
\hline \multirow{2}{*}{ Case } & \multirow{2}{*}{$K_{r}^{\prime}$ bot } & \multirow{2}{*}{$K_{t}^{\prime}$ top } & \multirow{2}{*}{$K_{r}^{\prime}$ top } & \multirow{2}{*}{$P_{\text {ua }}(\mathrm{kN})$} & \multicolumn{2}{|c|}{ Method A } & \multicolumn{2}{|c|}{ Method B } & \multicolumn{2}{|c|}{ Method C } \\
\hline & & & & & $P_{c}^{\prime}(\mathrm{kN})$ & $P_{\text {ua }} / P_{\text {ud }}$ & $P_{\mathrm{c}}{ }^{\prime}(\mathrm{kN})$ & $P_{\text {ua }} / P_{\text {ud }}$ & $P_{c}^{\prime}(\mathrm{kN})$ & $P_{\mathrm{ua}} / P_{\mathrm{ud}}$ \\
\hline 4.4.1 & 1 & 1 & 1 & 400 & 1560 & 1.05 & 1716 & 1.05 & 996 & 1.05 \\
\hline 4.4 .2 & $\infty$ & 0 & $\infty$ & 484 & & 1.03 & 1773 & 1.03 & 1389 & 1.03 \\
\hline 4.4 .3 & 1 & $\infty$ & 1 & 1092 & & 1.00 & 1727 & 1.00 & 996 & 1.15 \\
\hline
\end{tabular}

Table 7 shows that, for the first two columns, the three methods give the same results despite the differences in the compression capacity $P_{\mathrm{c}}{ }^{\prime}$ determined from the column curve. However, for the largest capacity column, Method C underestimates the ultimate load capacity by $15 \%$.

Two additional analysis results for this example are shown in Table 8.

Table 8 Additional results for columns with two equally spaced gravity loads

\begin{tabular}{|c|c|c|c|c|c|c|c|c|c|c|}
\hline \multirow{2}{*}{ Case } & \multirow{2}{*}{$\boldsymbol{K}_{r}^{\prime}$ bot } & \multirow{2}{*}{$K_{t}^{\prime}$ top } & \multirow{2}{*}{$K_{r}^{\prime}$ top } & \multirow{2}{*}{$P_{\text {ua }}(\mathbf{k N})$} & \multicolumn{2}{|c|}{ Method A } & \multicolumn{2}{|c|}{ Method B } & \multicolumn{2}{|c|}{ Method C } \\
\hline & & & & & $P_{c^{\prime}}(\mathrm{kN})$ & $P_{\mathrm{ua}} / P_{\mathrm{ud}}$ & $P_{c}^{\prime}(\mathrm{kN})$ & $P_{\mathrm{ua}} / P_{\mathrm{ud}}$ & $P_{\mathrm{c}}^{\prime}(\mathrm{kN})$ & $P_{\mathrm{ua}} / P_{\mathrm{ud}}$ \\
\hline 4.4.4 & $\infty$ & 3 & $\infty$ & 778 & 1560 & 1.04 & 1774 & 1.04 & 1389 & 1.05 \\
\hline 4.4 .5 & 3 & $\infty$ & 3 & 1396 & & 1.01 & 1757 & 0.99 & 1234 & 1.15 \\
\hline
\end{tabular}




\subsection{Columns with two unequally spaced gravity loads}

The example depicted in Figure 15(a) has two unequally spaced gravity loads, and is interesting in that Method A determines the middle segment of the column without rotational restraint (Case 4.5.1 in Table 9) to be critical while Method B and C invariably determine the bottom segment to be critical for both cases shown in Table 9. For Case 4.5.1, Method C determines the effective length factor of the bottom segment to be 3.2. Method A uses each segment length as its effective length, Method B uses the buckling model depicted in Figure 15(b), and Method C uses that depicted in Figure 15(a) minus the horizontal loads.

Table 9 Results for columns with unequally spaced gravity loads

\begin{tabular}{ccccccccc}
\hline \multirow{2}{*}{ Case } & \multirow{2}{*}{$\boldsymbol{K}_{\boldsymbol{r}}{ }_{\text {bot }}$} & $\boldsymbol{P}_{\text {ua }}(\mathbf{k N})$ & \multicolumn{2}{c}{ Method A } & \multicolumn{2}{c}{ Method B } & \multicolumn{2}{c}{ Method C } \\
\cline { 4 - 9 } & & $\boldsymbol{P}_{\mathbf{c}^{\prime}}(\mathbf{k N})$ & $\boldsymbol{P}_{\text {ua }} / \boldsymbol{P}_{\text {ud }}$ & $\boldsymbol{P}_{\mathbf{c}^{\prime}}(\mathbf{k N})$ & $\boldsymbol{P}_{\text {ua }} / \boldsymbol{P}_{\text {ud }}$ & $\boldsymbol{P}_{\mathbf{c}^{\prime}}(\mathbf{k N})$ & $\boldsymbol{P}_{\text {ua }} / \boldsymbol{P}_{\text {ud }}$ \\
\hline 4.5 .1 & 0 & 630 & 949 & 0.99 & 1767 & 0.99 & 603 & 1.11 \\
4.5 .2 & 3 & 1394 & 1802 & 0.96 & 1781 & 0.96 & 1279 & 1.13 \\
\hline
\end{tabular}

Although Methods A and B do not always determine the same segment to be critical, they yield essentially the same results that are accurate within 5\%. On the other hand, Method C underestimates the ultimate load capacities by more than $10 \%$.

\subsection{Columns subjected to primary bending moments}

All the preceding examples involve columns that are loaded concentrically, and are therefore subjected to secondary bending moments only due to the column's initial out-of-plumb and deflection (in addition to axial compression). The example depicted in Figure 16(a) is subjected to a primary bending moment due to a $200-\mathrm{mm}$ eccentricity of the axial load $P$. Depending on the eccentricity direction, the primary bending moment may act clockwise or counter-clockwise.

The "actual unsupported length" in Method A is the loaded length $L_{\mathrm{b}}$. Method B uses the buckling model shown in Figure 16(b), while Method C uses that shown in Figure 16(c).

It can be seen from Tables 10 and 11 that, whether the primary bending moment acts in the clockwise or counter-clockwise direction, the proposed Method B is consistently accurate with errors less than $10 \%$. In contrast, Methods A and C lead to errors of $15 \%$ or more in some cases. 
Table 10 Results for columns subjected to a clockwise primary bending moment

\begin{tabular}{|c|c|c|c|c|c|c|c|c|c|c|}
\hline \multirow{2}{*}{ Case } & \multirow{2}{*}{$\boldsymbol{K}_{r}^{\prime}$ bot } & \multirow{2}{*}{$K_{t}^{\prime}$ top } & \multirow{2}{*}{$K_{r}^{\prime}$ top } & \multirow{2}{*}{$P_{\text {ua }}(\mathbf{k N})$} & \multicolumn{2}{|c|}{ Method A } & \multicolumn{2}{|c|}{ Method B } & \multicolumn{2}{|c|}{ Method C } \\
\hline & & & & & $P_{\mathrm{c}}^{\prime}(\mathrm{kN})$ & $P_{\mathrm{ua}} / \boldsymbol{P}_{\mathrm{ud}}$ & $P_{\mathrm{c}}{ }^{\prime}(\mathrm{kN})$ & $P_{\mathrm{ua}} / \boldsymbol{P}_{\mathrm{ud}}$ & $P_{\mathrm{c}}^{\prime}(\mathrm{kN})$ & $P_{\mathrm{ua}} / P_{\mathrm{ud}}$ \\
\hline 4.6 .1 & 0 & $\infty$ & 0 & 564 & 1324 & 1.02 & 1600 & 0.97 & 1098 & 1.09 \\
\hline 4.6 .2 & 1 & $\infty$ & 1 & 861 & & 1.17 & 1721 & 1.04 & 1624 & 1.07 \\
\hline
\end{tabular}

Table 11 Results for columns subjected to a counter-clockwise primary bending moment

\begin{tabular}{|c|c|c|c|c|c|c|c|c|c|c|}
\hline \multirow{2}{*}{ Case } & \multirow{2}{*}{$K_{r}^{\prime}$ bot } & \multirow{2}{*}{$K_{t}^{\prime}$ top } & \multirow{2}{*}{$K_{r}^{\prime}$ top } & \multirow{2}{*}{$P_{\text {ua }}(\mathbf{k N})$} & \multicolumn{2}{|c|}{ Method A } & \multicolumn{2}{|c|}{ Method B } & \multicolumn{2}{|c|}{ Method C } \\
\hline & & & & & $P_{\mathrm{c}}{ }^{\prime}(\mathrm{kN})$ & $\boldsymbol{P}_{\text {ua }} / \boldsymbol{P}_{\text {ud }}$ & $P_{\mathrm{c}}{ }^{\prime}(\mathrm{kN})$ & $\boldsymbol{P}_{\text {ua }} / \boldsymbol{P}_{\text {ud }}$ & $P_{\mathrm{c}}{ }^{\prime}(\mathrm{kN})$ & $\boldsymbol{P}_{\text {ua }} / \boldsymbol{P}_{\text {ud }}$ \\
\hline 4.6 .3 & 0 & $\infty$ & 0 & 575 & 1324 & 1.08 & 1600 & 1.02 & 1098 & 1.15 \\
\hline 4.6 .4 & 1 & $\infty$ & 1 & 874 & & 1.22 & 1721 & 1.09 & 1624 & 1.11 \\
\hline
\end{tabular}

\subsection{Summary of analysis results}

The professional factors of the three methods for the columns analysed in the present work are plotted in Figure 17. The plots of the methods which are applied to a particular case are aligned vertically. Note that Method $\mathrm{C}$ is not relevant to the first thirteen cases, and the results in Table 2 obtained using an initial out-of-plumb $\xi$ equal to 0.004 in the second-order elastic analysis are not included. The statistical performance of the three methods are described by the box chart in Figure 18. Their summary values are given in Table 12.

Table 12 Mean professional factors

\begin{tabular}{ccc}
\hline \multirow{2}{*}{ Method } & \multicolumn{2}{c}{$\boldsymbol{P}_{\boldsymbol{u a}} / \boldsymbol{P}_{\boldsymbol{u d}}$} \\
\cline { 2 - 3 } & Mean & COV \\
\hline A & 1.15 & 0.12 \\
B & 1.00 & 0.03 \\
C & 1.09 & 0.05 \\
\hline
\end{tabular}

\section{Conclusions}

The notional load approach, in conjunction with second-order elastic analysis, was conceived in order to allow the use of the "actual unsupported length" of a column in its stability design check. However, in structural engineering practice, it is unclear what the unsupported length is for a segment of a column with intermediate gravity loads where no lateral restraints exist. The European drive-in rack design code prescribes a buckling model that mostly results in effective length factors greater than unity. This paper points out that, in the context of 
second-order elastic analysis based design procedure, not only the effective length factor of a segment without lateral restraints at both ends needs not be greater than unity, it can even be significantly less than unity.

It is explained that, since the destabilising effect due to the absence of a lateral restraint has been represented in the second-order analysis that incorporates the notional horizontal load (or the equivalent horizontal force), a notional horizontal restraint should be imposed onto the buckling model in determining the effective length to be used in the interaction equation.

Based on the results of plastic-zone analysis incorporating an initial out-of-plumb equal to 0.002, it was found that, while the actual (inelastic) effective length factor of a cantilevered column is 2.0, the use of the braced effective length factor equal to 0.7 in conjunction with the second-order elastic analysis incorporating an initial out-of-plumb equal to 0.004 still led to a slightly conservative result. When an initial out-of-plumb equal to 0.002 was used in the elastic analysis, the braced effective length factor gave essentially the same results as the unity effective length factor, which are close to the plastic-zone analysis results.

It is demonstrated through thirty examples involving columns subjected to concentrated gravity loads within their unsupported lengths that the proposed buckling model can lead to designs that are more economical than the use of the unity effective length factor or the buckling model described in the European drive-in rack design code. Automatically imposing notional horizontal restraints onto the buckling model where equivalent horizontal forces have been applied in the second-order analysis can be implemented in a computer program without much difficulty, with potentially significant savings in the total cost of the drive-in racking system or mill building columns.

\section{Acknowledgment}

The authors would like to thank the Australian Research Council for supporting the second author through the Discovery Early Career Researcher Award (Project ID: DE140100212).

\section{References}

[1] ECS. Steel static storage systems - Adjustable pallet racking systems, EN 15512. European Committee for Standardization; 2009.

[2] ERF. The design of drive-in and drive-through racking, FEM 10.2.07. European Racking Federation; 2012. 
[3] RMI. Specification for the design, testing and utilization of industrial steel storage racks, ANSI MH16.1-2012. Rack Manufacturers Institute; 2012.

[4] SA. Steel storage racking, AS 4084, Standards Australia; 2012.

[5] Liew JY, White DW, Chen WF. Notional-load plastic-hinge method for frame design. J Struct Eng 1994; 120:1434-1453.

[6] Clarke MJ, Bridge RQ. The notional load approach for the design of frames, Research Report No. R718, School of Civil and Mining Engineering, University of Sydney; 1995.

[7] ASCE. Effective length and notional load approaches for assessing frame stability: Implications for American steel design. Technical Committee on Load and Resistance Factor Design, American Society of Civil Engineers; 1997.

[8] SA. Steel structures, AS 4100-1998. Standards Australia; 1998.

[9] AISC. Specification for structural steel buildings, ANSI/AISC 360-10. American Institute of Steel Construction; 2010.

[10] White DW, Clarke MJ. Design of beam-columns in steel frames. 1. Philosophies and procedures. J Struct Eng 1997; 123(12):1556-1564.

[11] White DW, Clarke MJ. Design of beam-columns in steel frames. 2. Comparison of standards. J Struct Eng 1997; 123(12):1565-1575.

[12] White DW, Hajjar JF. Accuracy and simplicity of alternative procedures for stability design of steel frames. J Construct Steel Res 1997; 42(3):209-261.

[13] Surovek AE, White DW. Alternative approaches for elastic analysis and design of steel frames. I: Overview. J Struct Eng 2004; 130(8):1186-1196.

[14] Surovek AE, White DW. Alternative approaches for elastic analysis and design of steel frames. II: Verification studies. J Struct Eng 2004; 130(8):1197-1205.

[15] Tong GS, Xing G. A comparative study of alternative approaches for stability design of steel frames. Adv in Struct Eng 2007; 10(4):455-466.

[16] Tong GS, Zhang L, Xiang GR. Inelastic storey-buckling factor of steel frames. J Construct Steel Res 2009; 65:443-451.

[17] Gilbert BP, Rasmussen KJR. Drive-in steel storage racks I: Stiffness tests and 3D loadtransfer mechanisms. J Struct Eng 2012; 138(2):135-147.

[18] Fraser DJ, Bridge RQ. Buckling of stepped crane columns. J Construct Steel Res 1990; $16(1): 23-38$.

[19] MacCrimmon RA, Laurie-Kennedy DJ. Load and Resistance Factor Design and analysis of stepped crane columns in industrial buildings. Eng J 1997; 34(4):26-37.

[20] Schmidt JA. Design of mill building columns using notional loads. Eng J 2001; 38(2):90-99.

[21] Vasquez J, Riddell R. A simple stepped-column buckling model and computer algorithm. Eng J 2011; 48(1):19-30.

[22] Gilbert BP, Teh LH, Badet RX, Rasmussen KJR. Influence of pallets on the behaviour and design of steel drive-in racks. J Construct Steel Res 2014; 97:10-23.

[23] Dematic Pty Ltd. Rack Analysis \& Design (RAD) - User's Manual Version 6.9, 2009.

[24] Teh LH, Hancock GJ, Clarke MJ. Analysis and design of double-sided high-rise steel pallet rack frames. J Struct Eng 2004; 130(7):1011-1021.

[25] Bernuzzi C, Pieri A, Squadrito V. Warping influence on the static design of unbraced steel storage pallet racks. Thin-Walled Struct. 2014; 79:71-82. 
[26] Bernuzzi C, Gobetti A, Gabbianelli G, Simoncelli M. Unbraced pallet rack design in accordance with European practice-Part 1: Selection of the method of analysis. ThinWalled Struct. 2015; 86:185-207.

[27] Gere JM, Timoshenko SP. Mechanics of materials, Chapman \& Hall, London; 1991.

[28] Teh LH, Clarke MJ. Plastic-zone analysis of 3D steel frames using beam elements. J Struct Eng 1999; 125(11):1328-1337.

[29] SA/SNZ. Cold-Formed steel structures, AS/NZS 4600:2005. Standards Australia / Standards New Zealand; 2005.

[30] Bridge, R. Q., and Trahair, N. S. Limit state design rules for steel beam-columns. Steel Construction, Australian Institute of Steel Construction 1987; 21:2-11.

[31] Trahair, N. S., and Bradford, M. A. The behaviour and design of steel structures. E \& FN Spon; 1998.

[32] Key PW, Hancock GJ. A theoretical investigation of the column behaviour of coldformed square hollow sections. Thin-Walled Struct. 1993; 16:31-64.

[33] Strand7. User manual - Release 2.4.4, G+D Computing Pty Ltd; 2010. 


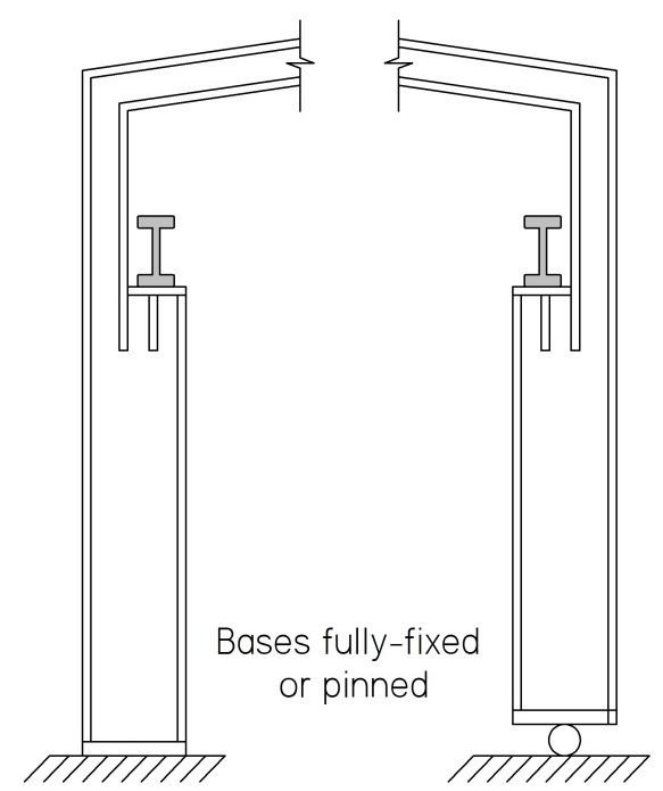

Figure 1 Mill building columns [18]

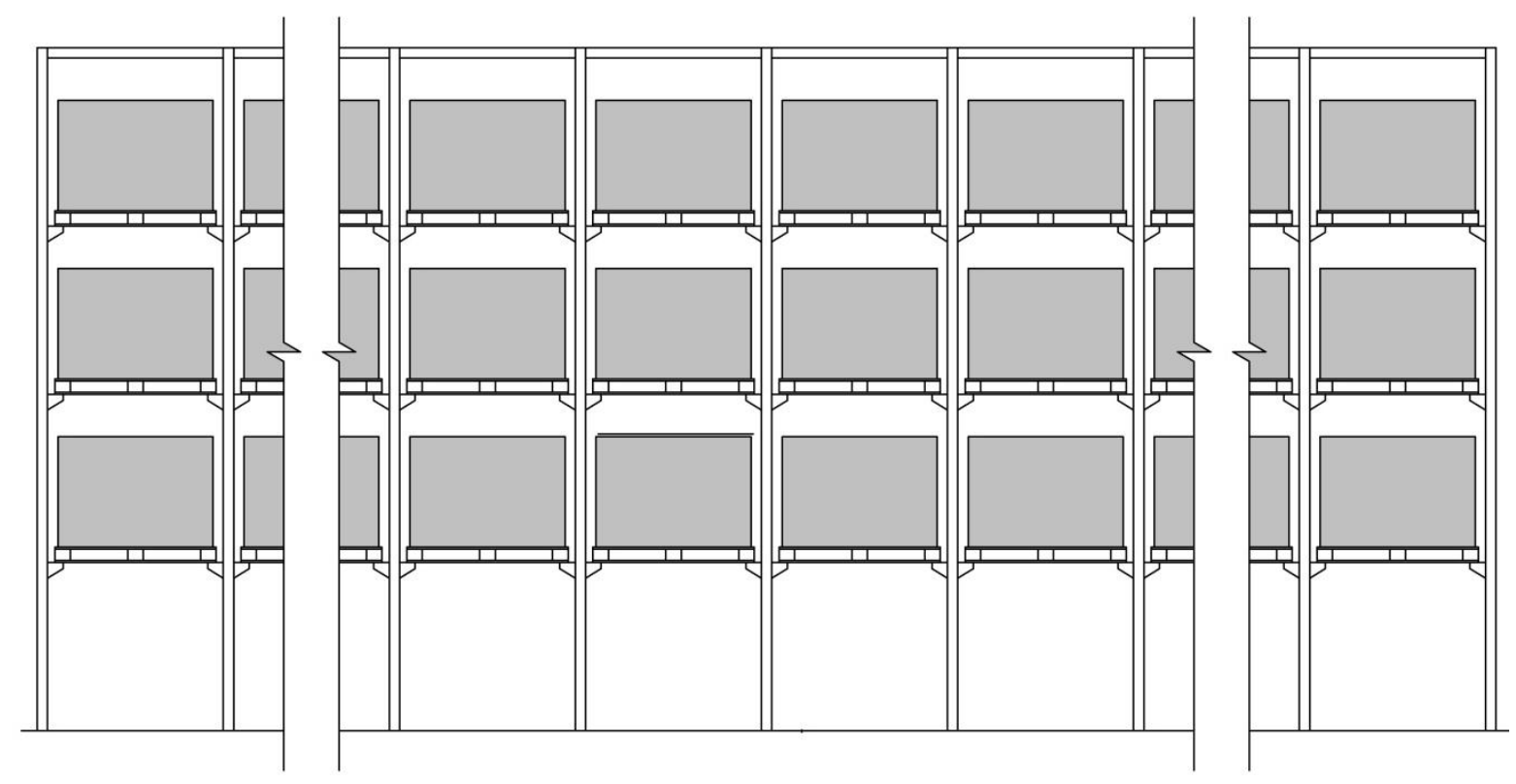

Figure 2 Design loading of drive-in rack uprights 


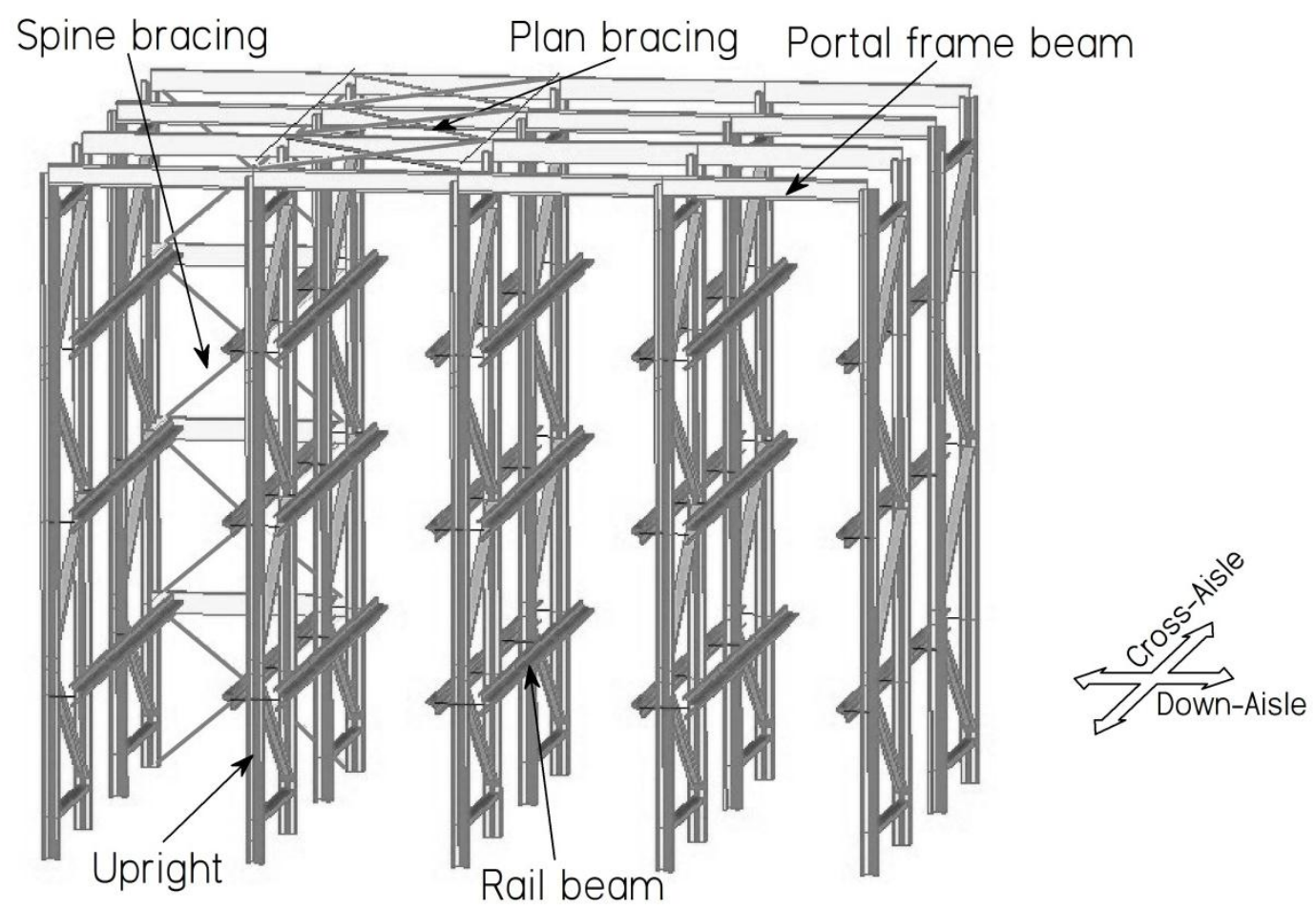

Figure 3 Three-dimensional view of a drive-in rack
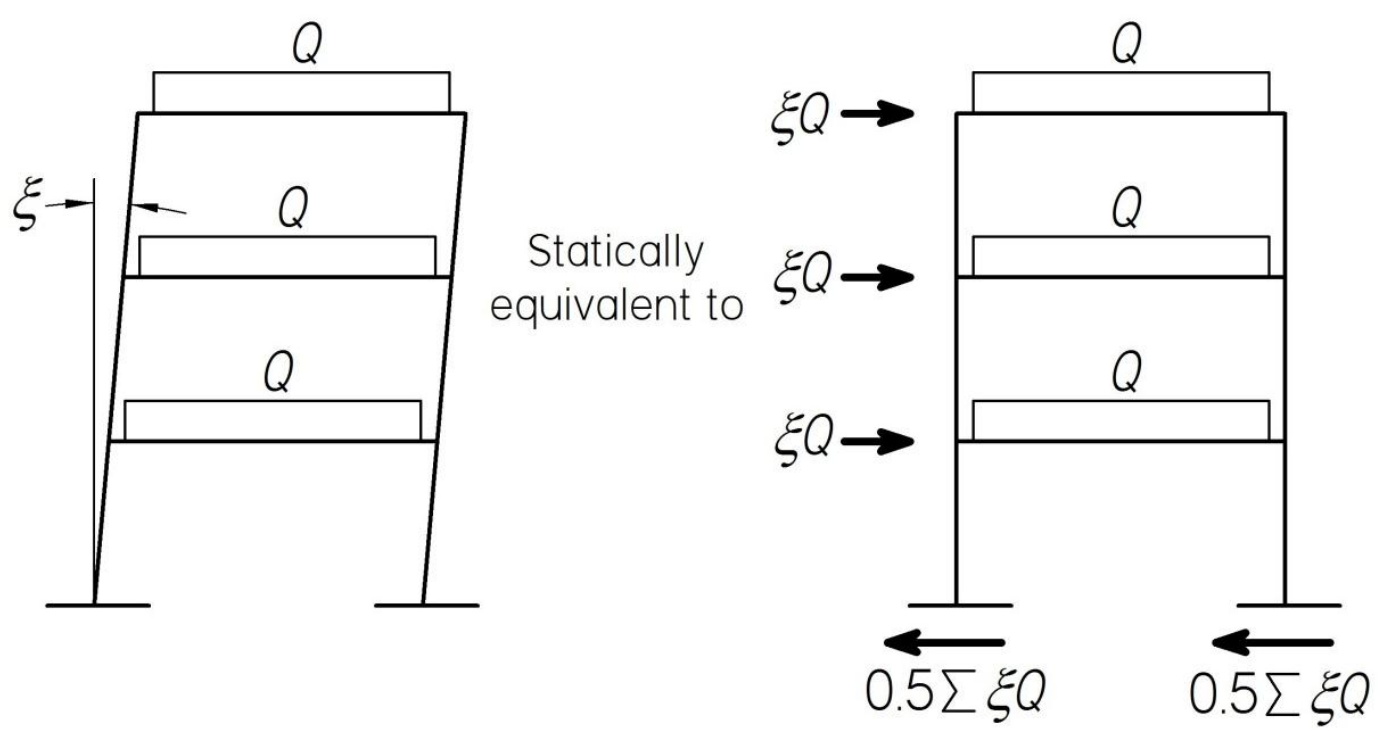

Figure 4 Equivalent horizontal forces [1] 


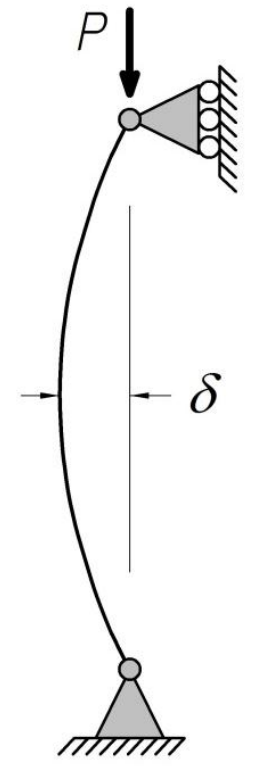

(a)

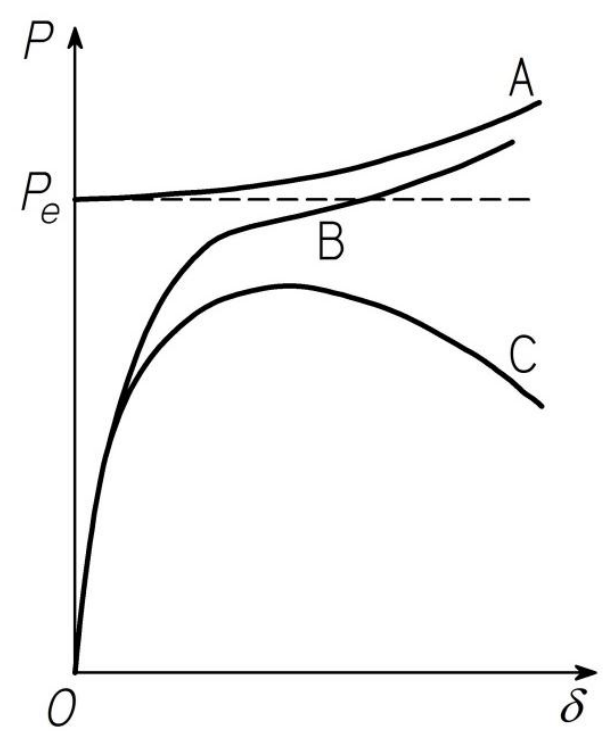

(b)

Figure 5 Behaviour and strength of a compact steel column [27]

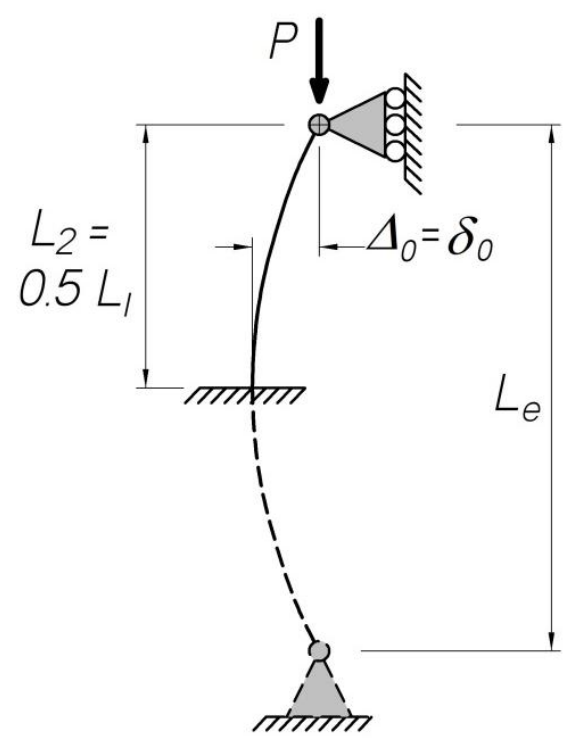

(a)

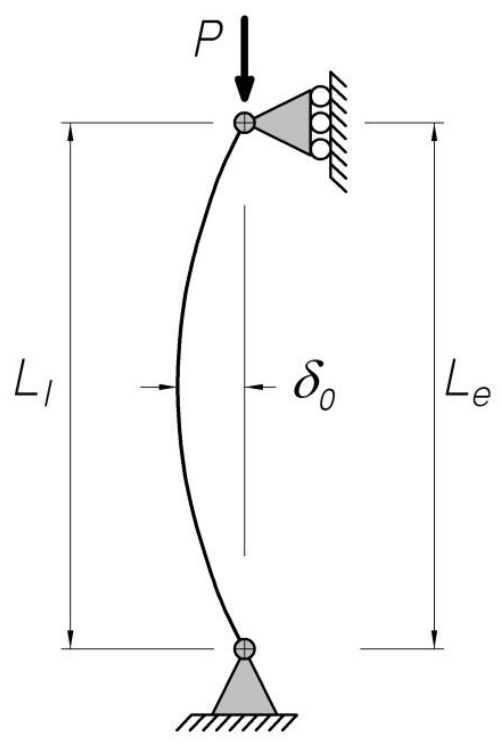

(b)

Figure 6 Two equivalent columns 

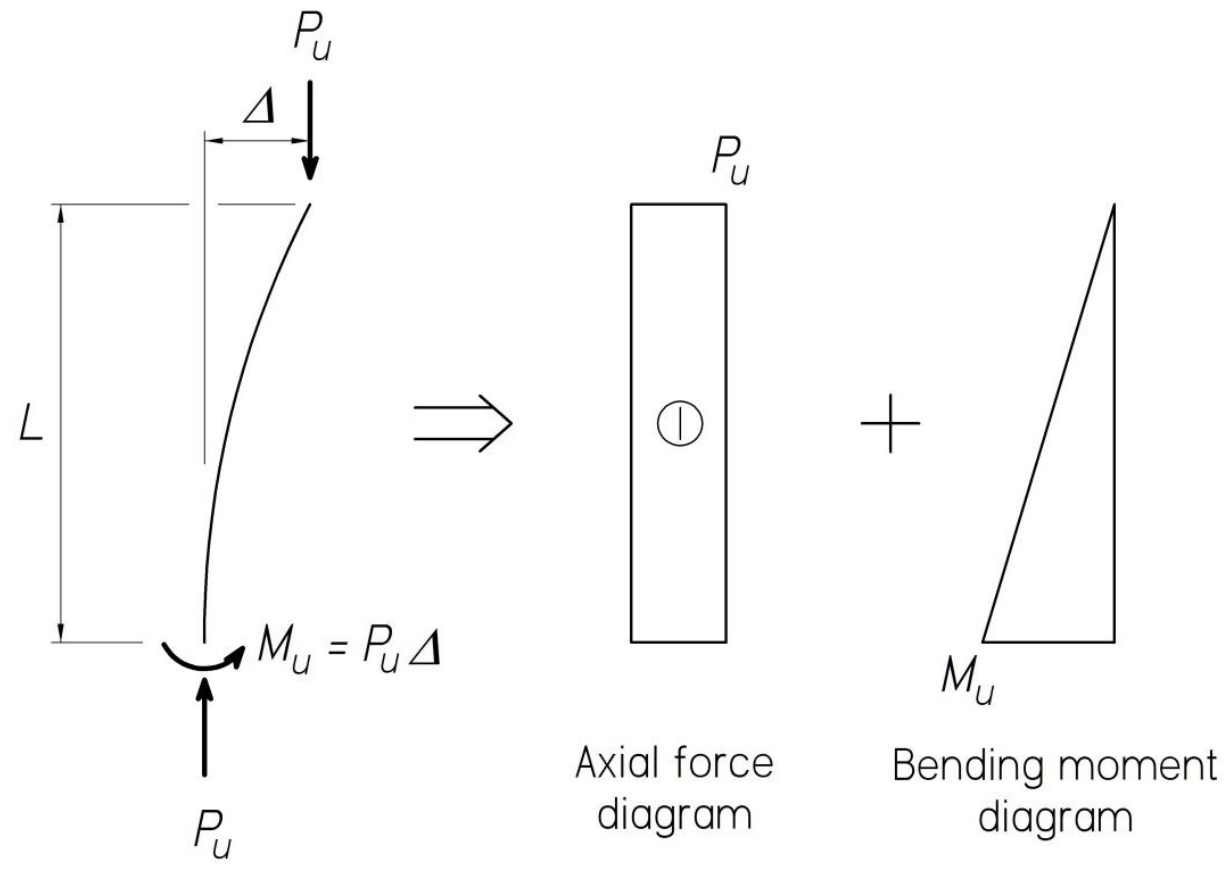

Free body diagram

Figure 7 Diagrams of a cantilevered column at the ultimate limit state

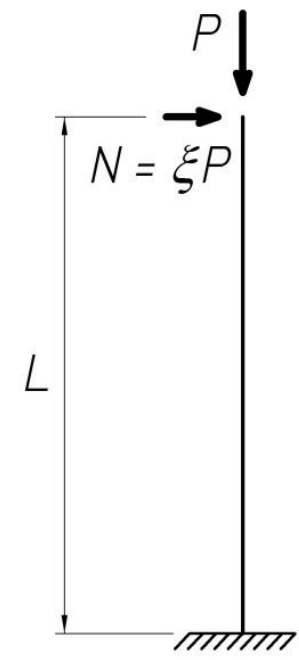

(a)

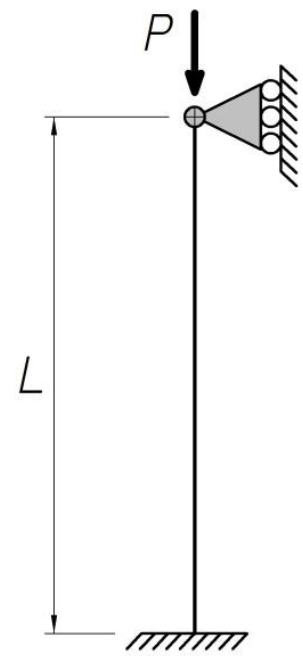

(b)

Figure 8 Problem 4.1 


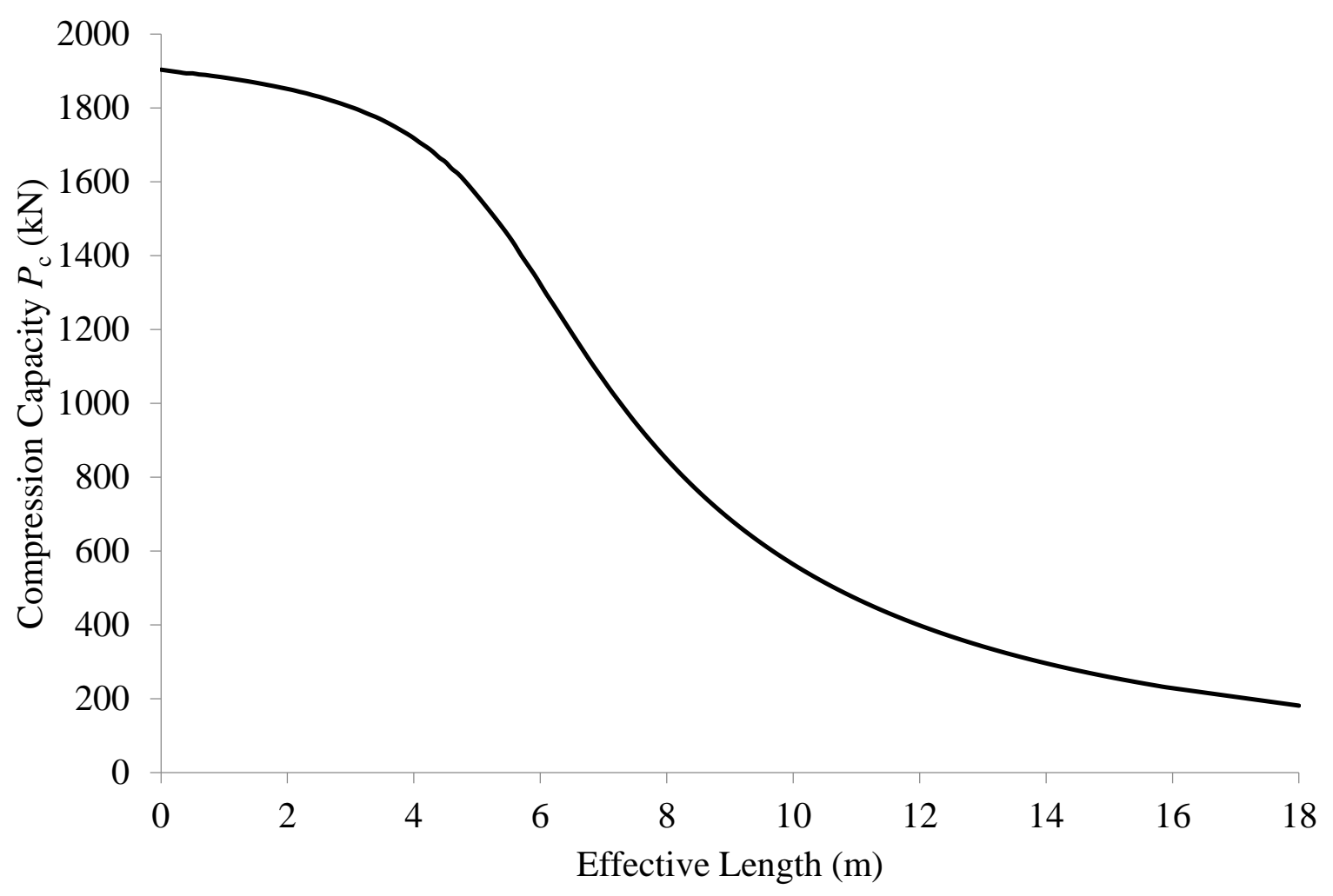

Figure 9 Column curve of SHS $203 \times 6.3$ (without residual stresses and strain hardening) 


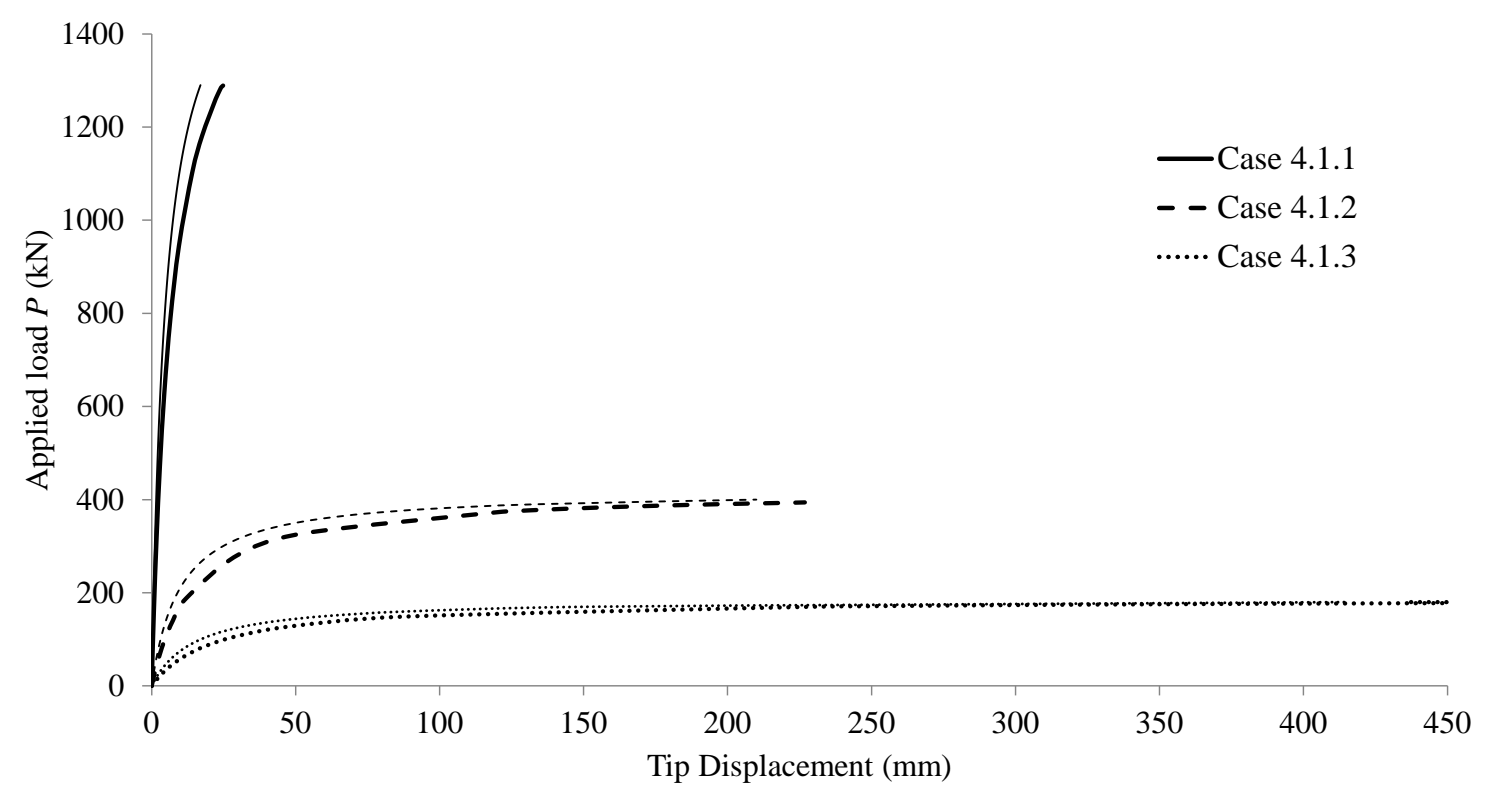

Figure 10 Elastic and inelastic load-deflection graphs of cantilevered columns

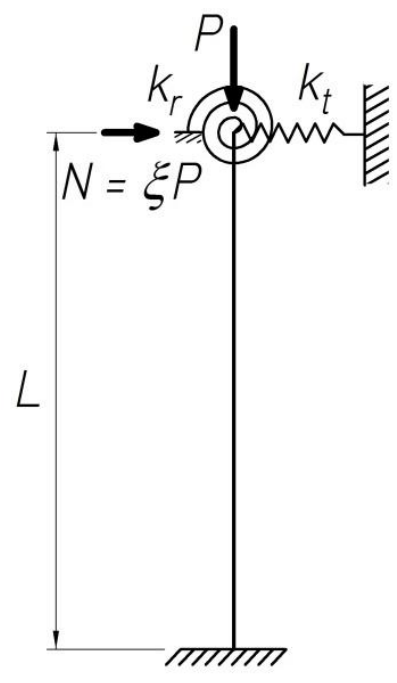

(a)



(b)

Figure 11 Problem 4.2 


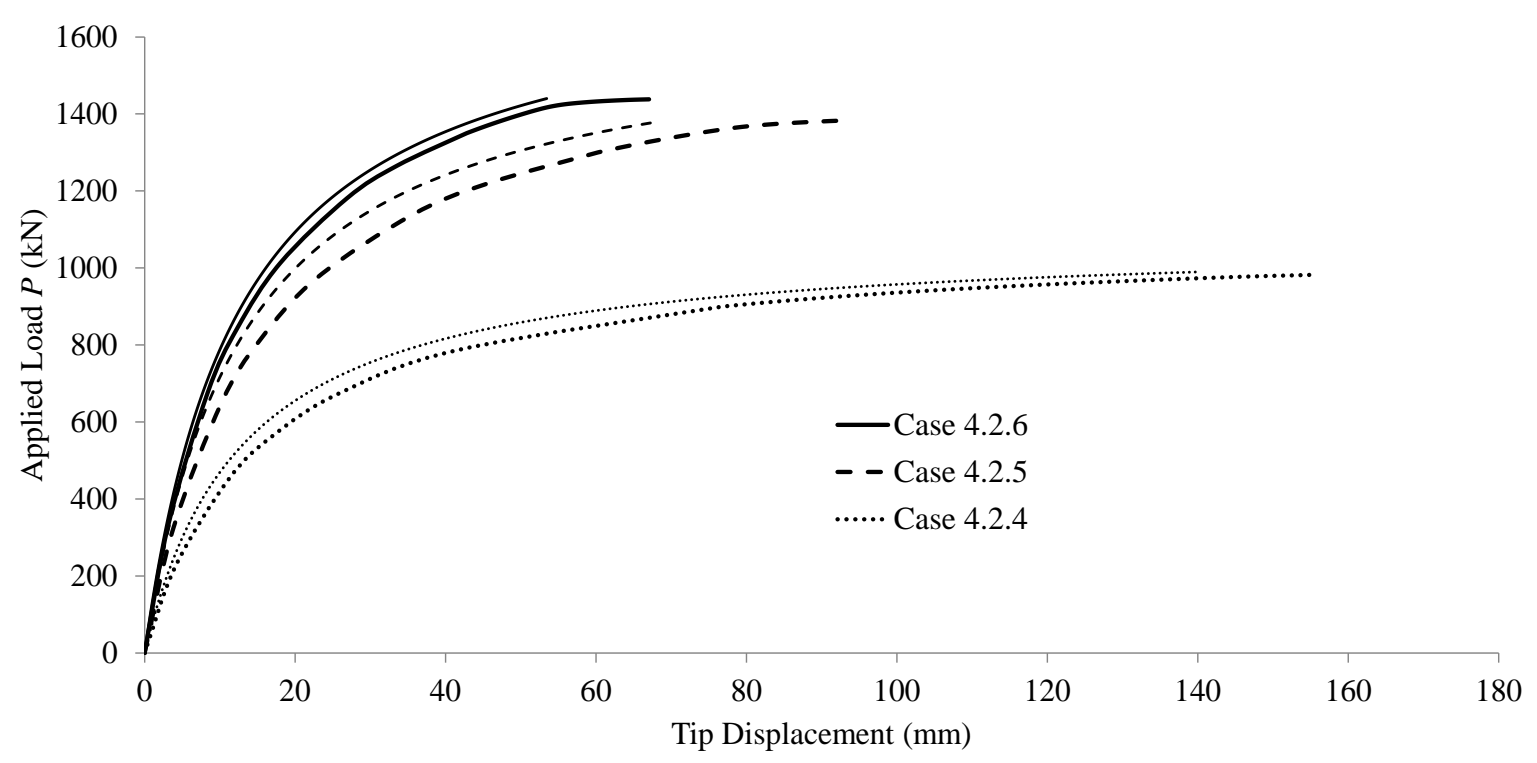

Figure 12 Elastic and inelastic load-deflection graphs of 7500-mm columns

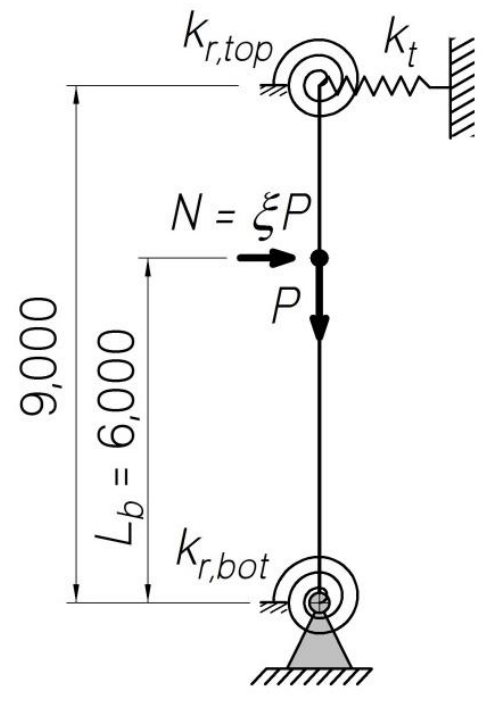

(a)



(b)



(c)

Figure 13 Problem 4.3 


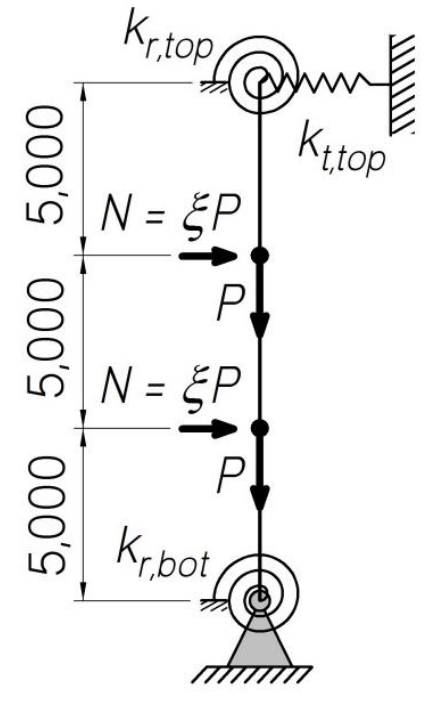

(a)

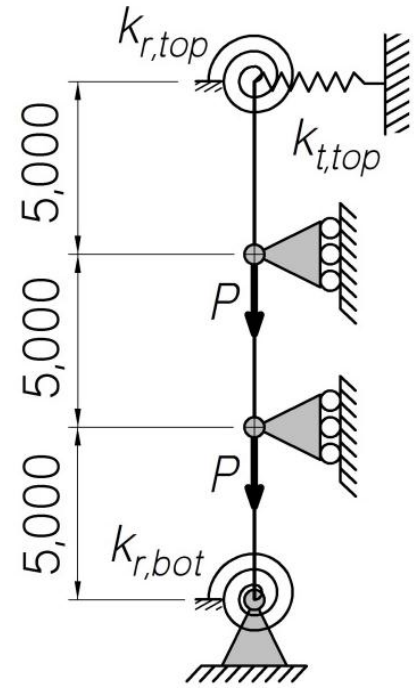

(b)

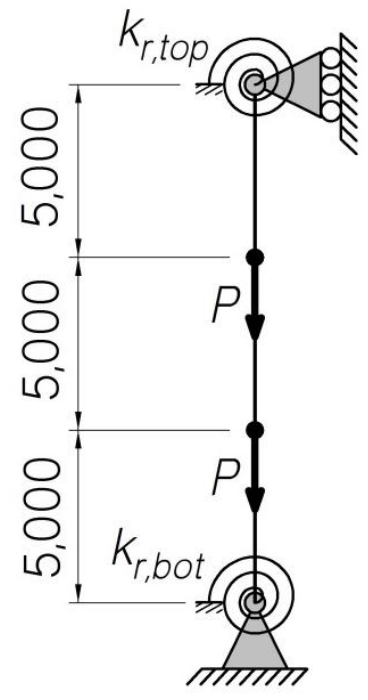

(c)

Figure 14 Problem 4.4

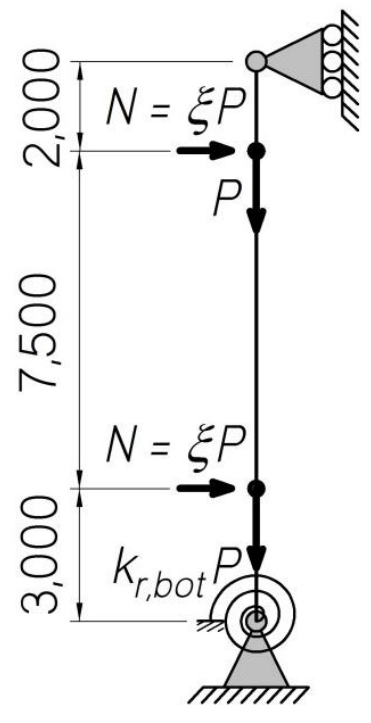

(a)

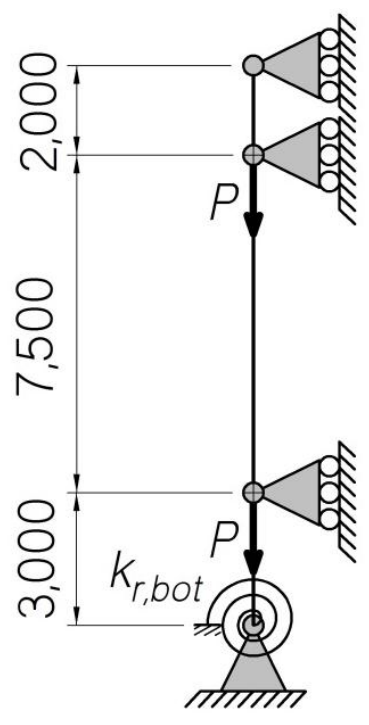

(b)

Figure 15 Problem 4.5 


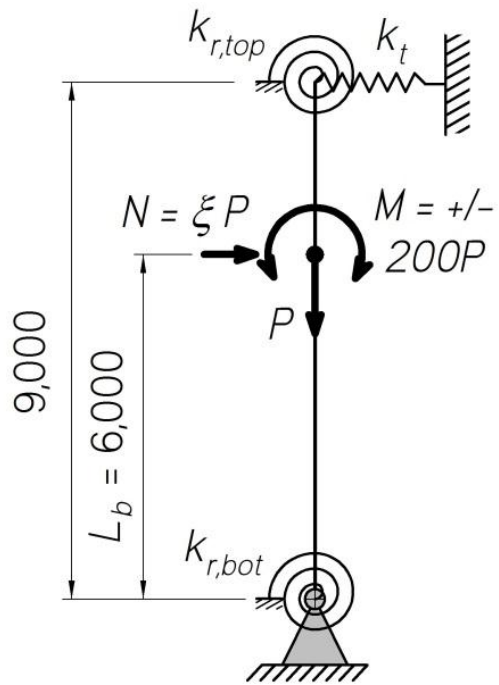

(a)



(b)

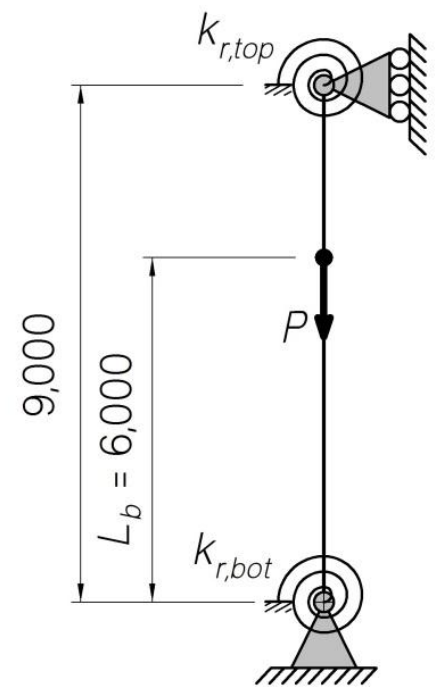

(c)

Figure 16 Problem 4.6

$$
P_{\text {ua }} / P_{\text {ud }}
$$

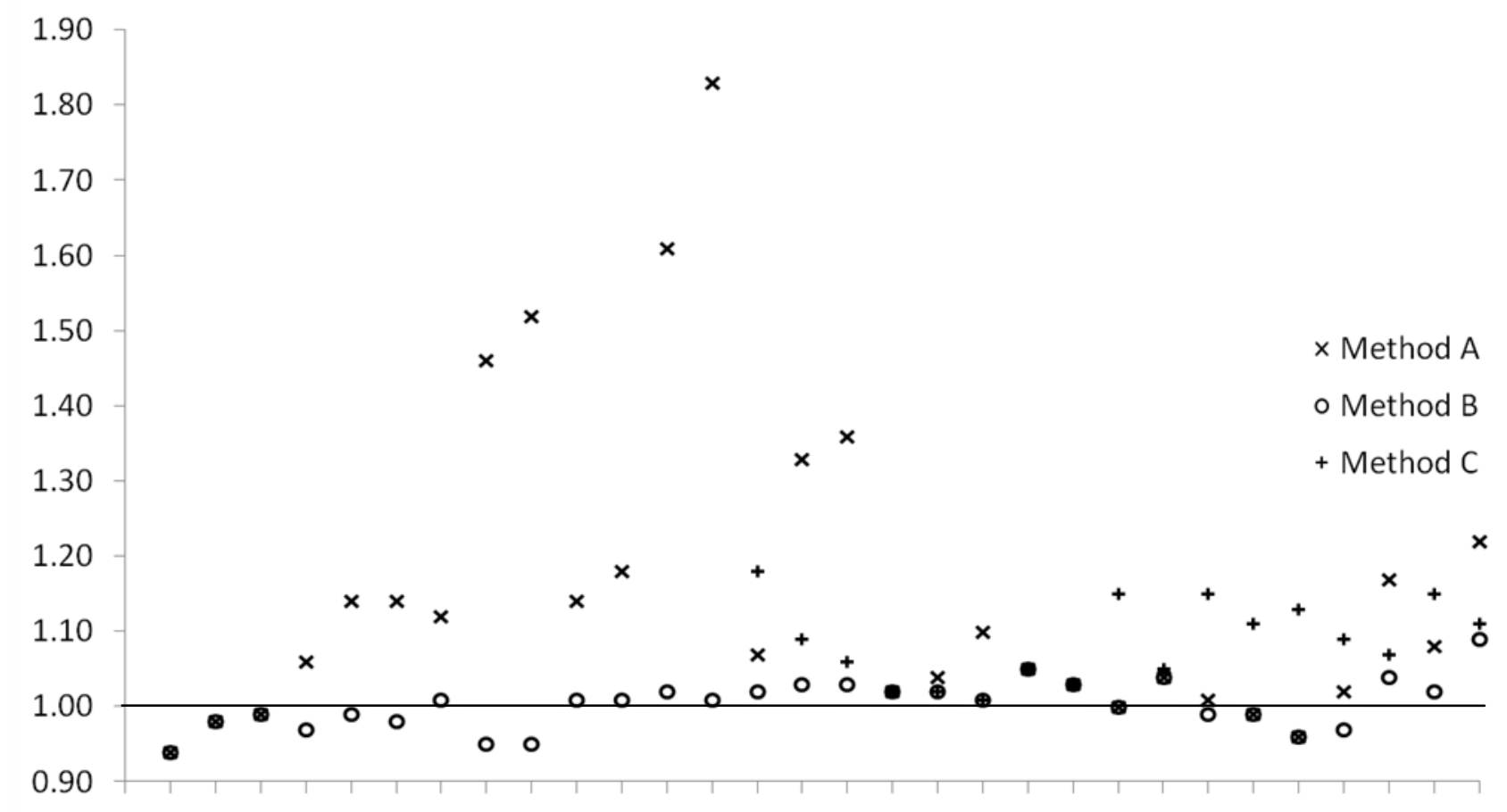






Figure 17 Professional factors of all methods

Figure 18 Box charts of professional factors 